\title{
The Epidemiological Aspects of Tuberculosis Patients in a Tertiary Care Medical College Hospital of Bangladesh
}

\author{
Abu Khalid Muhammad Maruf Raza ${ }^{1 *}$, Muhammad Rafiqul Islam², Mahfujun Nahar ${ }^{3}$ and Zaman Ahmed \\ ${ }^{1}$ Department of Pathology, Jahurul Islam Medical College, Kishoregonj, Bangladesh \\ ${ }^{2}$ National Institute of ENT, Dhaka, Bangladesh \\ ${ }^{3}$ Jahurul Islam Medical College Hospital, Kishoregonj, Bangladesh \\ ${ }^{4}$ Department of Pathology, Abdul Malek Ukil Medical College, Noakhali, Bangladesh
}

\begin{abstract}
Background and Aims: To assess the clinical and socio-demographic characteristics of tuberculosis patients in a tertiary care medical college hospital of Bangladesh.

Methods: An observational study was conducted over a period of one year from September 2015 to August 2016 in the Outpatient Department of Jahurul Islam Medical College Hospital and Department of Pathology, Jahurul Islam Medical College, Kishoregonj, The inclusion criteria of the study were pulmonary and extra pulmonary tuberculosis cases receiving antitubercular drugs therapy. Primary data from each patient was included in tuberculosis patient profile form such as age, gender, educational level, annual income in taka, occupational status and selected social habits like smoking, alcohol.

Results: Out of 112 patients studied, 50 (44.6\%) were male and $62(55.4 \%)$ were female. The majority of patients 69 $(61.7 \%)$ were in the age group of $15-34$ years. Annual family income of $78(69.6 \%)$ patients ranged between $36,000-$ $1,50,000$ taka. In total 112 patients $43(38.4 \%)$ were illiterate and 36 patients $(32.2 \%)$ were unemployed. $50 \%$ of the patients were smoker. The most common sites involved in extrapulmonary tuberculosis were the lymph nodes (38.2\%) followed by the pleura (36.4\%). The most common symptoms observed in pulmonary tuberculosis patients were cough with expectoration $(96.5 \%)$ followed by weight loss $(80.7 \%)$, fever $(73.7 \%)$ and loss of appetite $(54.4 \%)$

Conclusion: Prevalence of infection was noticed between PTB and EPTB with age and it was more common in younger age. However, based on our results TB control programme might usefully target young middle age populations for early diagnosis of TB to decrease TB morbidity and mortality.
\end{abstract}

Keywords: Tuberculosis; Pulmonary tuberculosis; Extra pulmonary tuberculosis

\section{Introduction}

Tuberculosis (TB) remains a major global public health problem [1]. It is estimated that about one-third of the world's population is infected with mycobacterium tuberculosis [2]. After primary infection, TB may reactivate at anytime and anywhere in the body. Recent studies have suggested that the sites of extra-pulmonary tuberculosis (EPTB) may vary according to geographic location and population [3-5]. Clinical manifestations of TB are variable and depend on a number of factors that are related to the microbe, the host and the environment [6]. Tuberculosis (TB) is one of the leading causes of mortality and morbidity among infectious diseases worldwide and has an enormous economic impact on many countries [7]. Bangladesh is one of the highest TB burden countries accounting for one fifth of the global incidence of TB [8]. The disease is more prevalent in the productive age group of 15-54 years which causes an economic burden on the individual's household when they fall sick. The number of TB patients is increasing at a horrifying speed for several reasons. One is the lack of awareness of the disease, which makes patients neglect their symptoms till it is too late. For many they fear that they will surely die of TB and are therefore unable to accept the fact. Another very important reason for hiding the truth is the social stigma attached to TB. Women are thrown out of families, people lose their jobs and children's are thrown out of school because of the irrational belief that TB is fatal and will kill all those who live in proximity to a TB patient. Once removed from the family, these people have a seriously diminished quality of life and die on the streets due to complications of the disease and starvation [9]. Extra pulmonary TB occurs outside the lungs; in lymph nodes and in any organ system even brain and reproductive organs. The bacteria may spread through lymphatic or haematogenous dissemination. The TB bacteria may remain dormant for years at a particular site before causing the disease and may have a wide variety of clinical manifestations leading to difficulty and delay in its diagnosis [10]. Epidemiological information on $\mathrm{TB}$ is required to plan control and prevention strategies and to inform service delivery systems. Assessment of the epidemiological indices within a specific time period can also help planners to focus on the main problems of a community and to assess the efficacy of preventive programs. Given the reasons provided, the aim of present study was to determine the epidemiological and sociodemographic status of TB in a tertiary medical college hospital in Bangladesh.

\section{Methods}

An observational study was conducted over a period of one year from September 2015 to August 2016 in the Outpatient Department of Jahurul Islam Medical College Hospital and Department of Pathology, Jahurul Islam Medical College, Kishoregonj, Bangladesh. A total of 112 patients, who came to outpatient department were interviewed. The

*Corresponding author: Abu Khalid Muhammad Maruf Raza, Department of Pathology, Jahurul Islam Medical College, Bajitpur, Kishoregonj, Bangladesh, Tel: +8801711306123; E-mail: drmarufraza@gmail.com

Received November 18, 2016; Accepted January 23, 2017; Published January 27, 2017

Citation: Raza AKMM, Islam MR, Nahar M, Ahmed Z (2017) The Epidemiological Aspects of Tuberculosis Patients in a Tertiary Care Medical College Hospital of Bangladesh. J Pulm Respir Med 7: 389. doi: 10.4172/2161-105X.1000389

Copyright: (c) 2017 Raza AKMM, et al. This is an open-access article distributed under the terms of the Creative Commons Attribution License, which permits unrestricted use, distribution, and reproduction in any medium, provided the original author and source are credited. 
Citation: Raza AKMM, Islam MR, Nahar M, Ahmed Z (2017) The Epidemiological Aspects of Tuberculosis Patients in a Tertiary Care Medical College Hospital of Bangladesh. J Pulm Respir Med 7: 389. doi: 10.4172/2161-105X.1000389

Page 2 of 4

inclusion criteria of the study were pulmonary and extra pulmonary tuberculosis cases diagnosed on the basis of sputum smear, culture, chest-radiograph, cytological and histopathological examination receiving antitubercular drugs therapy. Patients unwilling to participate in the study were excluded from the study. Informed consent was taken for the study. Patient's informed consent form including information regarding the study was provided to the patients for their understanding about the study and participation. Patient informed consent was written in Bengali language. Primary data from each patient was included in tuberculosis patient profile form such as age, gender, educational level, annual income in taka, occupational status and selected social habits like smoking, alcohol.

\section{Classification of PTB and EPTB patients}

It is well known that lymph node and pleural involvement in TB is a direct extension of the disease from lung parenchyma. Therefore, patients with exclusively intrathoracic involvement (i.e., confined to lung parenchyma, pleura, and intrathoracic lymph nodes) were considered as PTB for the purpose of this analysis. Patients with extension of disease to organs or tissues outside the thorax, including those patients who also had pulmonary involvement, were considered as EPTB in our analysis. We followed the definitions used in two earlier studies $[3,4]$ for EPTB and PTB patients.

\section{Results}

Out of 112 patients studied, 50(44.6\%) were male and 62 (55.4\%) were female. The majority of patients $69(61.7 \%)$ were in the age group of 15-34 years (Table 1 ).

Annual family income of $78(69.6 \%)$ patients ranged between 36,000 tk to $1,50,000$ tk. In total 112 patients 43 (38.4\%) were illiterate and 36 patients $(32.2 \%)$ were unemployed. $50 \%$ of the patients were smoker Among them 53.5\% had pulmonary tuberculosis (Table 2).

The most common sites involved in extrapulmonary tuberculosis were the lymph nodes $(38.2 \%)$ followed by the pleura $(36.4 \%)$. The most common symptoms observed in pulmonary tuberculosis patients were cough with expectoration (96.5\%) followed by weight loss $(80.7 \%)$, fever $(73.7 \%)$ and loss of appetite $(54.4 \%)$. Whereas in extrapulmonary tuberculosis patients majority had weight loss (79.6\%), fever $(67.3 \%)$ loss of appetite (61.2\%). Both pulmonary and extrapulmonary patients had fever $(83.3 \%)$ and loss of appetite $(66.7 \%)$ as major clinical symptom (Table 3 ).

\begin{tabular}{|c|c|c|c|c|c|}
\hline \multirow[b]{2}{*}{ Characteristics } & \multicolumn{3}{|c|}{ Number of patients } & \multirow{2}{*}{$\begin{array}{c}\text { Total Number } \\
\text { of patients }(N=112)\end{array}$} & \multirow[b]{2}{*}{ Percentage (\%) } \\
\hline & Pulmonary $(\mathrm{N}=57)$ & Extra pulmonary $(\mathrm{N}=49)$ & $\begin{array}{l}\text { Pulmonary and Extra } \\
\text { pulmonary }(\mathrm{N}=6)\end{array}$ & & \\
\hline \multicolumn{6}{|l|}{ Gender } \\
\hline Male & 31 & 16 & 3 & 50 & 44.6 \\
\hline Female & 26 & 33 & 3 & 62 & 55.4 \\
\hline \multicolumn{6}{|l|}{ Age group(years) } \\
\hline $5-14$ & - & 3 & 1 & 4 & 3.6 \\
\hline $15-24$ & 17 & 16 & 1 & 34 & 30.4 \\
\hline $25-34$ & 14 & 19 & 2 & 35 & 31.3 \\
\hline $35-44$ & 6 & 5 & - & 11 & 9.8 \\
\hline $45-64$ & 16 & 5 & 1 & 22 & 19.6 \\
\hline$>64$ & 4 & 1 & 1 & 6 & 5.3 \\
\hline
\end{tabular}

Table 1: Age and gender distribution of the study subjects.

\begin{tabular}{|c|c|c|c|c|c|}
\hline \multirow[b]{2}{*}{ Characteristics } & \multicolumn{3}{|c|}{ Number of patients } & \multirow{2}{*}{$\begin{array}{c}\text { Total Number } \\
\text { of patients }(\mathrm{N}=112)\end{array}$} & \multirow{2}{*}{$\begin{array}{c}\text { Total Percentage } \\
(\%)\end{array}$} \\
\hline & Pulmonary $(\mathrm{N}=57)$ & Extra pulmonary $(\mathrm{N}=49)$ & $\begin{array}{l}\text { Pulmonary and Extra } \\
\text { pulmonary }(\mathrm{N}=6)\end{array}$ & & \\
\hline \multicolumn{6}{|l|}{ Employment status } \\
\hline Employed & 25 & 19 & 3 & 47 & 41.9 \\
\hline Unemployed & 16 & 18 & 2 & 36 & 32.2 \\
\hline Retired & 5 & 1 & - & 6 & 5.3 \\
\hline Student & 11 & 11 & 1 & 23 & 20.6 \\
\hline \multicolumn{6}{|l|}{ Social Habits } \\
\hline Smokers & 36 & 12 & 8 & 56 & 50 \\
\hline Alcoholic & 3 & 2 & 1 & 6 & 5.3 \\
\hline Nonsmokers & 20 & 28 & 2 & 50 & 44.6 \\
\hline \multicolumn{6}{|l|}{ Education } \\
\hline None & 23 & 19 & 1 & 43 & 38.4 \\
\hline Primary & 16 & 13 & 2 & 31 & 27.7 \\
\hline High school & 10 & 7 & 1 & 18 & 16.1 \\
\hline University & 8 & 10 & 2 & 20 & 17.8 \\
\hline \multicolumn{6}{|c|}{ Annual family income(Taka) } \\
\hline $36,000-1,00,000$ & 21 & 18 & 4 & 39 & 34.8 \\
\hline $1,01,000-1,50,000$ & 23 & 15 & 1 & 39 & 34.8 \\
\hline $1,51,000-2,00,000$ & 8 & 12 & 4 & 24 & 21.5 \\
\hline$>2,00,000$ & 5 & 4 & 1 & 10 & 8.9 \\
\hline
\end{tabular}

Table 2: Socio-demography and other characteristics of tuberculosis patients. 


\begin{tabular}{|c|c|c|c|}
\hline Characteristics & Pulmonary $(\%)(\mathrm{N}=57)$ & Extra pulmonary $(\%)(\mathrm{N}=49)$ & Pulmonary+Extra pulmonary $(\%)(\mathrm{N}=6)$ \\
\hline Cough with expectoration & $55(96.5 \%)$ & $20(40.8 \%)$ & $03(50 \%)$ \\
\hline Loss of appetite & $31(54.4 \%)$ & $30(61.2 \%)$ & $04(66.67 \%)$ \\
\hline Fever & $42(73.7 \%)$ & $33(67.3 \%)$ & $05(83.33 \%)$ \\
\hline sweating & $19(33.3 \%)$ & $06(12.2 \%)$ & $01(16.67 \%)$ \\
\hline chills & $27(47.4 \%)$ & $22(44.9 \%)$ & $03(50 \%)$ \\
\hline Fatigue & $25(43.9 \%)$ & $11(22.4 \%)$ & $04(66.67 \%)$ \\
\hline Weight loss & $24(42.1 \%)$ & $15(30.6 \%)$ & $02(33.33 \%)$ \\
\hline Chest pain & $04(7.0 \%)$ & $13(26.5 \%)$ & - \\
\hline Abdominal pain & $19(33.3 \%)$ & $11(22.4 \%)$ & $03(50 \%)$ \\
\hline Breathlessness & $13(22.8 \%)$ & $19(38.8 \%)$ & $04(66.67 \%)$ \\
\hline Swelling & - & $16(32.7 \%)$ & - \\
\hline Body ache & $13(22.8 \%)$ & $18(36.7 \%)$ & $01(16.67 \%)$ \\
\hline
\end{tabular}

Table 3: Clinical presentation of patients with pulmonary and extra pulmonary tuberculosis.

\section{Discussion}

The TB incidence is one of the most important surveillance indicators in public health. Pulmonary tuberculosis is an air born infectious disease caused by Mycobacterium tuberculosis and is a major cause of morbidity and mortality particularly in developing countries. In this study a total of 112 diagnosed TB patients undergoing treatment were studied. Of these $50(44.6 \%)$ were males and $62(55.4 \%)$ were females, which suggests that the number of female patients are more compared to male patients which is similar to a study conducted by Othman et al. [11]. This could be because women often face some obstacles such as high female illiteracy, ill health with lower immune status, massive house hold work load and economic dependency that allow them limited access to health care. This gender differences observed in our study may be a consequence of gender differences in both exposures to TB infection and prevalence of susceptibility risk factors (e.g., smoking). Of the 112 tuberculosis patients evaluated, $69(61.7 \%)$ patients were within the age group of $15-34$ years. This shows that TB mainly infects the productive age group constituting to a strong economic burden and affect their working potentiality. These could be due to differences in prevalence of host-related factors or important co-exposures like smoking and tobacco exposure. It should be noted that reproductive age group has strong implications in tuberculosis control strategies because of higher chances of mother to child transmission and higher probability of complications because of attendant antenatal and postnatal morbidity. A large number of study populations were illiterate 43 (38.4\%). As level of education is an important factor in with knowledge about disease, educational status of the community is one of the key factors for the success or failure of the treatment in tuberculosis. In the present study, $41.9 \%$ were employed. The educational level and employment status of this study was found consistent with the studies from Brazil conducted by Steffen et al. [12]. Only $10(8.9 \%)$ of the patients had annual family income more than 2 lacs taka which shows tuberculosis affects middle class and lower class economic population group. Unemployment, lower Educational Level, unhealthy living environment and overcrowding living condition may be the reason for TB in lower socio economic class people. This study show $56(50 \%)$ of the patients are smoker suggesting smoking is one of the main risk factor for TB. This is consistent with a meta-analysis which reported that smoking is a risk factor for TB infection and for pulmonary TB disease. Furthermore, behavioural factors especially cigarette smoking and alcohol use have negative effect on TB treatment. Cigarette smoking is known to damage the lungs and suppress the individual adaptive immune responses affecting patient's response to TB treatment. In our study 50.9\% patients had pulmonary tuberculosis, $43.7 \%$ patients had extra pulmonary tuberculosis and $5.4 \%$ were both pulmonary and extrapulmonary tuberculosis. Pulmonary tuberculosis was more common than extra pulmonary tuberculosis. This study also show pulmonary tuberculosis is more common in men $(54.4 \%)$ than in women $(45.6 \%)$. The same result was also observed in a study by Noertjojo et al. [13]. Recent studies have suggested that the sites of extrapulmonary tuberculosis may vary according to geographic location and population. It is well known that lymph node and pleural involvement in TB is a direct extension of the disease from lung parenchyma [14]. In this study the most common sites involved in extrapulmonary tuberculosis were the lymph nodes (38.2\%) followed by the pleura (36.4\%) which is consistent with the study from Nepal conducted by Sreeramareddy et al. [15]. The signs and symptoms of pulmonary TB are typical and known (cough and sputum) whereas extra pulmonary TB is difficult to identify not only by the patients but also by the clinicians themselves [16]. In this study $96.5 \%$ of patients of pulmonary TB and $40.8 \%$ patients of extrapulmonary TB has cough with expectoration which was also observed in similar study [15].

\section{Conclusion}

Our study concludes that majority of the tuberculosis patients are within the economically productive age group ranged between 15-34 years. Females are the majority of the patients with extra pulmonary tuberculosis while pulmonary tuberculosis predominantly occurred in men. The most common sites of involvement were the lymph nodes followed by pleura, spine and genitourinary tract. Based on this results TB control programme might usefully target young and female populations for early diagnosis to decrease tuberculosis morbidity and mortality.

\section{References}

1. World Health Organization (WHO) Global tuberculosis control. WHO report 2002.

2. Sudre P, ten Dam G, Kochi A (1992) Tuberculosis: a global overview of the situation today. Bull World Health Organ 70: 149-159.

3. Yang Z, Kong Y, Wilson F, Foxman B, Fowler AH, et al. (2004) Identification of risk factors for extrapulmonary tuberculosis. Clin Infect Dis 38: 199-205.

4. Musellim B, Erturan S, Sonmez Duman E, Ongen G (2005) Comparison of extra-pulmonary and pulmonary tuberculosis cases: factors influencing the site of reactivation. Int J Tuberc Lung Dis 9: 1220-1223.

5. Ilgazli A, Boyaci $H$, Basyigit I, Yildiz F (2004) Extrapulmonary tuberculosis: clinical and epidemiologic spectrum of 636 cases. Arch Med Res 35: 435-441.

6. (2000) Diagnostic standards and classification of tuberculosis in adults and children. Am J Respir Crit Care Med 161: 1376-1395

7. Anunnatsiri S, Chetchotisakd P, Wanke C (2005) Factors associated with treatment outcomes in pulmonary tuberculosis in northeastern Thailand. Southeast Asian J Trop Med Public Health 36: 324-330. 
Citation: Raza AKMM, Islam MR, Nahar M, Ahmed Z (2017) The Epidemiological Aspects of Tuberculosis Patients in a Tertiary Care Medical College Hospital of Bangladesh. J Pulm Respir Med 7: 389. doi: 10.4172/2161-105X.1000389

Page 4 of 4

8. http://apps.who.int/iris/bitstream/10665/137094/1/9789241564809_eng.pdf

9. Batra S (2008) Improving the health care delivery through global collaboration. Operation ASHA-fighting Tuberculosis in India.

10. Gonzalez OY, Adams G, Teeter LD, Bui TT, Musser JM, et al. (2003) Extrapulmonary manifestations in a large metropolitan area with a low incidence of tuberculosis. Int J Tuberc Lung Dis 7: 1178-1185.

11. Othman GQ, Ibrahim MIM, Raza YA (2011) Comparison of the clinical and socio-demographical factors in pulmonary and extra pulmonary tuberculosis patients in Yemen. J Clin Diagn Res 5: 191-195.

12. Steffen R, Menzies D, Oxlade O, Pinto M, de Castro AZ, et al. (2010) Patients' costs and cost-effectiveness of tuberculosis treatment in DOTS and non-DOTS facilities in Rio de Janeiro, Brazil. PLoS One 5: e14014.
13. Noertjojo K, Tam CM, Chan SL, Chan-Yeung MM (2002) Extra-pulmonary and pulmonary tuberculosis in Hong Kong. Int J Tuberc Lung Dis 6: 879-886.

14. Khazaei S, Roshanaei G, Saatchi M, Rezaeian S, Zahiri A, et al. (2014) The epidemiological aspects of tuberculosis in Hamadan Province during 2005-1. Int J Health Policy Manag 2: 75-80.

15. Sreeramareddy CT, Panduru KV, Verma SC, Joshi HS, Bates MN (2008) Comparison of pulmonary and extrapulmonary tuberculosis in Nepal- a hospital-based retrospective study. BMC Infect Dis 8: 8.

16. Muniyandi M, Ramachandran R, Balasubramanian R, Narayanan PR (2006) Socio-economic dimensions of tuberculosis control: review of studies over two decades from Tuberculosis Research Center. J Commun Dis 38: 204-215. 